\title{
WHITE SPOT OF PINEAPPLES
}

\author{
By Meuvule T. Coor, Plant Pathologist, \\ Insular Experiment Station, Río Piedras, P. R.
}

This disease was reported from Puerto Rico by G. L. Fawcett of the Porto Rico Agrieultural Experiment Station (Mayagüez) in 1908, who described it as follows:

"The pineapple has one conspicuous disease characterized by the appearance of white spots on the leaves. This is caused in many cases at least by the entrance of organisms through wounds such as the punctures made by sucking insects. At first the spots are small and brown. Gradually they enlarge, the epidermis sinks, the interior tissue is destroyed, and the white bleached appearance is taken on. It is in no sense a serious disease although common under exeessively moist conditions."

Nowell (1922) says:

"A leaf-spot which is fairly common in the West Indies has been investigated by L. D. Larsen in Hawaii. It occurs on well-grown plants and its effect on their development is not usually appreciable. It has been shown to be due to the infection of insect and spine punctures, or other injuries, by the fungus Thielaviopsis. Infection and development depend on the prevalence of moist and eloudy weather or on the shading of the plants.",

Larsen of Hawaii published a bulletin on diseases of pineapples in 1910 in which he described what appears to be the same disease as follows :

"The spots vary considerably, as regards size, shape and color. Many are large and white, and are noticeable from along distance, while otlers are small and inconspicuous. In typical mature spots there is a straw colored central area surrounded by a dark margin. Very often there is a dark center within the straw colored area, or darls blotches, due to the formation of the black macrospores within the tissue, may be scattered over it in an irregular manner. Sometimes long white arms extend beyond the dark border, and, again, the entire spot may be white or straw colored throughout. The internal tissue is soft and decayed at first, but this soon dries out, leaving the injured area dry and slirunken. The white or straw-colored area is not due simply to drying of the affected tissue, as is often the case witl similar diseases, but comes on while the tissue is still quite firm, and long before it has begun to dry out. In early stages the spots may be olive brown in color and fairly regular in outline, or they may be white and irregular from the start. The size of the spots inereases very rapidly, so that in two or three days what was a small brown spot will have become from two to six inches in length. Even twelve inches is not an unusual length." 
Larsen believed these spots to be due to Thielaviopsis paradoxa which gained entrance to the plant through slight wounds. He said:

"The fungus, Thielaviopsis, which as we have seen causes Soft Rot of the pineaple fruit and Base Rot of the cuttings, is also responsible for a conspicuous disease of the leaves of this plant. It attacks the leaves through surface wounds made by insects and by the spines and sharp edges of neighboring leaves, and produces large discolorations or spots which often spread across the entire leaf and thereby kill all that part of the leaf which is above the spot. The spots may be found in almost any of our pineapple fields during the winter months, and at times become exceedingly numerous. They are most prevalent in the finest fields where the plants are green and vigorous, while in poor fields and on yellow plants they are more rare."

$\mathrm{He}$ conducted experimental work on which this conclusion was based and which demonstrated that the fungus could not gain entrance to the plant except through wounds. He also made very interesting studies on the influence of weather which he described as follows :

"In the infection experiments conducted it was found that when inoculations were made in the presence of bright sunlight, or if the leaves were exposed to sunny and dry weather conditions on the following day, but very few of the inoculations would take. It was therefore necessary when inoculating leaves under such conditions to cover the wounds with grafting wax or paraffin. When the plants were shaded or when cloudy weather existed after inoculation, infection took place very readily without such protection. Direct sunlight prevents infection; first by drying out the wounds, and secondly, by killing the spores of the fungus. In the experiment mentioned on page 15 it was found that the most resistant form of Thielaviopsis spores are killed in a few hours when exposed to direct sunlight. With this in view it is evident why the spots are scarcely known during the dry summer season and yet become very numerous in the winter months.

"The size of the spots is also governed largely by weather conditions. Sunlight and dry weather, after infection has taken place, tend to limit the size while moist and cloudy weather has the opposite effect. In our infection experiments when the plants were well shaded the entire leaf would often become involved.

"It was furthermore noted that the typical white condition would make its appearance only on leaves that were exposed to sunlight. When inoculated plants were kept in the shade the spots would invariably be brown in color and very regular in outline, whereas when exposed to sunlight the white and irregular patches would appear. They appeared, however, in a sporadic manner, occurring on one leaf here and another there, while other leaves inoculated at the same time and equally exposed would show none of it. It was at first thought that this white appearance was a distinct trouble due to some cause other than Thielaviopsis, but judging from the results of our infection experiments such does not appear to be the case."

A very pronounced outbreak of this disease in the vicinity of Co- 
rozal was called to the attention of the writer in August of 1932. These plantings were at an elevation of about 350 or 375 feet and on the boundary line between limestone soils of the coastal plain and the volcanic acid soils.

There had been heavy rainfall and the disease appeared in such abundance that the grower became very much alarmed. The fungus (Thielaviopsis paradoxa), which is well known as a parasite on a number of species of plants in Puerto Rico, had been reported previously to the writer as the cause of a very serious fruit rot in this locality. The symptoms, the weather conditions and the presence of the fungus, conformed with Larsen's Hawaiian report of 1910.

A large amount of the diseased leaves were collected and taken to the laboratory for study. A study of free-hand sections did not show a fungus. A large number of cultures were made but the fungus did not develop in any of them. Thielaviopsis paradoxa grows readily in culture and the writer has isolated it many times from decaying pineapple fruits, slips, sugar cane, coconuts and other plants, using the same medium as was used at this time. Material was then prepared for paraffing sectioning and staining but the results were again negative. It was impossible to conduct inoculation work at the Experiment Station, owing to lack of plants.

When the rainfall was reduced and bright sunshine prevailed for a few days, no new spots were formed. This was followed by another period of rainy weather and another outbreak of the disease. Therefore, it appears from these studies that these spots may be the results of weather conditions without the influence of any other agency. Field studies by the writer did not indicate that a puncture by a spine, insect or any other agency was necessary for the formation of these spots. 